\title{
Direitos humanos e a formação de professores que ensinam Ciências
}

\author{
Human rights and the training of teachers who teach science
}

\author{
Ana Carla de Souza ${ }^{1}$ \\ Erllon Rodolfo Viegas Barata² \\ Nívia Magalhães da Silva Freitas ${ }^{3}$ \\ Nadia Magalhães da Silva Freitas ${ }^{4}$
}

\section{Resumo}

Temáticas como dignidade da pessoa humana, necessidades e direitos humanos, e também aquelas relacionadas a princípios e a valores como liberdade, respeito, igualdade, justiça e não discriminação, entre outras, precisam adentrar os espaços de formação de professores, com a perspectiva de reafirmar e de disseminar os princípios relativos aos direitos humanos. O trabalho de pesquisa, desenvolvido no contexto do tema "Relações entre Ciência, Sociedade e Cidadania II", junto aos discentes do Curso de Licenciatura Integrada em Educação em Ciências, Matemática e Linguagens, da Universidade Federal do Pará, objetivou apreender em que termos uma experiência formativa, envolvendo "a afirmação dos direitos humanos", contribui para a necessária problematização do seu oposto "a violação dos direitos humanos". Para tal, utilizamos fotos reproduções que apresentavam situações degradantes com seres humanos. Trouxemos para este artigo, as ponderações de dois licenciandos, relativas ao trabalho infantil, para problematizar os desdobramentos vinculados à violação dos direitos humanos e à dignidade humana, as quais foram apreciadas a luz da análise interpretativa. Nesse processo, observamos que a cultura da relativização das situações que implicavam em violação dos direitos humanos foi, naquele momento, abandonada. A postura frente à experiência formativa voltou-se à sensibilidade para a condição humana.

Palavras-chave: Direitos humanos; formação de professores que ensinam ciências; trabalho infantil.

\section{Abstract}

Themes such as dignity of the human person, needs and human rights, as well as those related to principles and values such as freedom, respect, equality, justice and non-discrimination, need to penetrate the spaces of teacher training, with the perspective of reaffirming and disseminate human rights principles. The research, developed in the context of the theme "Relations between Science, Society and Citizenship II", with the students of the Integrated Degree Course in Science, Mathematics and Language Education, at the Federal University of Pará, aimed apprehending as a formative experience, involving "the affirmation of human rights", contributes to the necessary problematization of its opposite "the violation of human

\footnotetext{
1 Universidade Federal do Pará | caarlasoouza.cs@gmail.com

2 Universidade Federal do Pará | erlon.rodolfo@gmail.com

3 Universidade Federal do Pará | nivia.bio2015@gmail.com

4 Universidade Federal do Pará | nadiamsf@yahoo.com.br
} 
rights". We used photograph reproductions that presented degrading situations with human beings, to foment the problematization about the situations. We brought to this article the analysis of the appreciations of two graduates, regarding infantile work, to problematize the violation of human rights and human dignity, which were valued in the light of interpretative analysis. In this process, we observed that the culture of relativization of situations that implied a violation of human rights was, at that time, abandoned. The attitude towards formative experience has turned to sensitivity to the human condition.

Keywords: Human rights; teacher training; infantile work.

\section{Introdução}

Proposições aos direitos humanos ocorreram em resposta aos horrores das duas guerras mundiais, principalmente aos eventos ocorridos na segunda guerra mundial, a exemplo das "[...] tentativas 'científicas' em escala industrial de extermínios dos judeus e dos outros povos considerados 'inferiores' pelos nazistas [...] [e do] lançamento da bomba atômica sobre Hiroshima e Nagasaki" (TOSI; FERREIRA, 2014, p. 37). É a Organização das Nações Unidas (ONU) que tem a missão de garantir a não deflagração de uma terceira guerra mundial e, ao mesmo tempo, promover a paz entre os países. Nesse contexto, um dos primeiros atos da Assembleia Geral da ONU referiu-se à proclamação da Declaração Universal dos Direitos Humanos (DUDH), em 10 de dezembro de 1948, em Paris (TOSI; FERREIRA, 2014).

A DUDH enuncia trinta artigos (BRASIL, 1998), apresentando em seu conteúdo os aspectos que delineiam as condições para assegurar a dignidade humana e o respeito concreto às liberdades fundamentais de todo e qualquer ser humano. A questão da dignidade humana está posta na Constituição Federal (BRASIL, 2016, p. 5), vejamos:

Art. $1^{\circ}$ A República Federativa do Brasil, formada pela união indissolúvel dos Estados e Municípios e do Distrito Federal, constitui-se em Estado Democrático de Direito e tem como fundamentos: [...];

III - a dignidade da pessoa humana; [...].

A Constituição toma como um dos seus fundamentos, a prioridade pela proteção dos direitos fundamentais de seus cidadãos, mediante a dignidade da pessoa humana. Assim, "[...] reconheceu na dignidade pessoal a prerrogativa de todo ser humano em ser respeitado como pessoa, de não ser prejudicado em sua existência (a vida, o corpo e a saúde) e de fruir de um âmbito existencial próprio" (AWAD, 2006, p. 113). Assim, ao tomarmos a dignidade da pessoa humana como valor basilar da sociedade, reconhece-se que o ser humano é o centro e o fim do direito (AWAD, 2006). A DUDH constitui-se mais um valor ético, que propriamente um instrumento de ordem jurídica; mas, é a partir dela que se observaram mudanças no comportamento social mundial (GORCZEVSKI; KONRAD, 2013).

A DUDH fundamenta-se nos valores de cidadania, democracia e participação dos indivíduos na construção de uma sociedade que deve se orientar pela busca de igualdade e 
de solidariedade (BRASIL, 1998). Os princípios contemplados na DUDH, portanto, situam-se na [...] confluência democrática entre os direitos e liberdades individuais e os deveres para com a comunidade em que se vive (BRASIL, 2007). A própria Constituição Federal, de 1988, é pautada em vários valores expressos na DUDH (BRASIL, 2016). Certamente, a perspectiva é estimular uma cultura de direitos humanos no país, que é firmada pela consolidação da "[...] democracia, do desenvolvimento, da justiça social e da construção da paz" (CHINELLI; OLIVEIRA, 2017, p. 76).

Destacamos o artigo $3^{\circ}$ da DUDH, qual seja, "Todo ser humano tem direito à vida, à liberdade e à segurança pessoal". Compreendemos que o alicerce dos direitos humanos pauta-se no direito à vida, mesmo porque do que valeria os demais direitos se este não preponderasse (BRASIL, 2007). Ao destacarmos o artigo $3^{\circ}$ da DUDH, fazemo-lo para expressar nossa contrariedade frente ao atual cenário de violação de direitos, em referência, principalmente, ao direito a vida, o qual se encontra relacionado ao princípio da dignidade humana, erigido como fundante da Constituição Federal (BRASIL, 2006), pressuposto para todos os demais princípios. Portanto, temos a clareza que os direitos humanos são universais, indivisíveis e inter-relacionados, de modo que se houver o desrespeito a qualquer um deles, a concretização dos demais fica comprometida (BRASIL, 2007).

É nesse contexto, que se faz necessário educar em direitos humanos, no sentido de problematizar as múltiplas questões que revelam sua violação, face às circunstâncias degradantes vivenciadas por muitas pessoas na sociedade. No cenário brasileiro, lamentavelmente, os direitos básicos, como direito à saúde, à alimentação e à educação são cotidianamente violados, logo, uma educação em direitos humanos é fundamental.

Cabe destacar, que o Brasil teve sua construção sobre bases europeias, assim como a educação escolar também está baseada em uma cultura eurocêntrica, o que por muito tempo silenciou/silencia "[...] vozes, saberes, cores, crenças e sensibilidades" (OLIVEIRA; QUEIROZ, 2013. p. 9). Dessa forma, uma educação em direitos humanos oportuniza que sujeitos que foram historicamente subjugados tenham voz e/ou sejam reconhecidos como sujeitos de direito, mesmo em um contexto escolar que ainda continua homogeneizando aqueles que adentram seu espaço, o que resulta no desprezo de culturas e na opressão de identidades (OLIVEIRA; QUEIROZ, 2013).

Os Direitos Humanos são assim considerados:

[...] são os direitos e liberdades básicas de todos os seres humanos, independentemente de raça, gênero, idade, deficiência, condições de mobilidade, orientação sexual, identidade de gênero, nacionalidade, religião, territorialidade, cultura ou qualquer outra condição. Os direitos humanos abrangem os direitos civis, os direitos políticos, os direitos econômicos, sociais e culturais, além dos direitos de solidariedade (BRASIL, 2018a, p. 2).

É importante, "[...] promover o conhecimento dos direitos humanos de modo que sejam percebidos não só como direito, mas também como dever de promoção de todos para a 
garantia da paz social no mundo" (GORCZEVSKI; KONRAD, 2013). É bem verdade, que a "[...] educação voltada aos direitos humanos ainda não faz parte da prática nem do currículo da escola brasileira" (FERNANDES; PALUDELO, 2010, p. 233). Entretanto, é essencial empreender nessa tarefa, para que os direitos humanos, com seus princípios e valores, sejam internalizados por todos aqueles que vivem os espaços educacionais.

A DUDH constitui-se um documento cuja força ética fomentou a criação de muitos outros documentos e acordos para garantir a materialização dos seus princípios e valores, representando a base de muitos sistemas de proteção dos direitos humanos, contribuindo, assim, para a construção de uma cultura de direitos humanos (BRASIL, 2007; TOSI; FERREIRA, 2014). Em realidade, os Direitos Humanos representam, no seu conjunto, um dos componentes fundamentais da sociedade contemporânea, que "Afirmados ou negados, exaltados ou violados, eles fazem parte da nossa vida pessoal e coletiva" (CANDAU; SACAVINO, 2013, p. 59). Assim, uma "[...] educação em ciências que não vá ao encontro dos Direitos Humanos é uma educação vazia e pouco contribui para a humanidade" (OLIVEIRA, 2013, p. 20).

A Base Comum Curricular (BNCC) traz elementos que justificam a necessidade de abordagem aos direitos humanos no ensino de ciências, ao considerarmos que constituem aportes para o exercício da cidadania, nos seguintes termos:

[...] ao longo do Ensino Fundamental, a área de Ciências da Natureza tem um compromisso com o desenvolvimento do letramento científico, que envolve a capacidade de compreender e interpretar o mundo (natural, social e tecnológico), mas também de transformá-lo com base nos aportes teóricos e processuais das ciências. Em outras palavras, apreender ciência não é a finalidade última do letramento, mas sim, o desenvolvimento da capacidade de atuação no e sobre o mundo, importante ao exercício pleno da cidadania (BRASIL, 2017, p. 321).

Ao ponderar sobre os aspectos acima apresentados na BNCC (BRASIL, 2017), temos a considerar, conforme Marshall (1967), que o exercício da cidadania apresenta-se vinculado aos direitos humanos em seus diferentes domínios, deste modo, insere-se, assim, na perspectiva de desconstrução da cultura de violações.

É importante que temáticas como dignidade da pessoa humana, necessidades e direitos humanos, e também aquelas relacionadas a princípios e a valores como liberdade, respeito, igualdade, justiça e não discriminação, entre outras, adentrem os espaços de formação de professores, com a perspectiva de reafirmar e disseminar os direitos humanos. No que diz respeito à educação em ciências, há que se problematizar e se contrapor [...] aos mecanismos de dominação e opressão (MONTEIRO; SOUZA, 2016, p. 336), tão presentes na nossa sociedade, de modo que possamos nos aproximar do campo social, a despeito da compreensão, que cabe ao professor ensinar a boa ciência, entendida aqui como abordagem extensiva de conteúdos, sem, entretanto, alcançar um aspecto fundamental - a vida. Assim, o trabalho de pesquisa, ora apresentado, objetivou apreender em que termos uma 
experiência formativa, envolvendo a afirmação dos direitos humanos, contribui para a necessária problematização do seu oposto "a violação dos direitos humanos".

\section{Caminhos metodológicos da pesquisa}

A abordagem de pesquisa configurou-se como de natureza qualitativa (MINAYO, 2016). A investigação se deu no contexto do desenvolvimento do tema "Relações entre Ciência, Sociedade e Cidadania II", do Curso de Licenciatura Integrada em Ciências, Matemática e Linguagens, da Universidade Federal do Pará, voltado para a formação de professores dos anos iniciais. Cabe destacar, que a proposta curricular do Curso em que a pesquisa ocorreu, está organizada por eixos temáticos, temas e assuntos, numa perspectiva interdisciplinar.

O objeto de conhecimento central do tema em questão está relacionado aos Direitos Humanos. Assim, propiciamos um conjunto de atividades que buscaram contribuir para o reconhecimento de diferentes situações de desrespeito à dignidade humana. Para fins deste artigo, trouxemos a análise da atividade que utilizou fotos reproduções, de domínio público, disponíveis na internet, que apresentavam situações com seres humanos, objetivando problematizar as referidas situações. Nessa perspectiva, o estudo apoiou-se na entrevista estruturada, modalidade projetiva, apresentada como uma técnica que utiliza "[...] dispositivos visuais, como filmes, vídeos, pinturas, gravuras, fotos, poesias, contos e redações de outras pessoas [...] modalidade [que] constitui um convite ao entrevistado para discorrer sobre o que vê ou lê" (MINAYO, 2016, p. 59).

Os licenciandos foram convidados a escolher uma foto reprodução, as quais estavam relacionadas à violação dos direitos humanos, precisamente aquela que mais the chamasse atenção. A partir disso, e apoiados em algumas orientações de Afonso (2005), apresentamos algumas questões, quais sejam: por que você escolheu esta fotografia? O que você acha que o fotografo quis mostrar? Há nessa fotografia alguma coisa que lhe é familiar? O que será que essas pessoas da fotografia sentem? Como viverão a sua vida? Terão desejos diferentes dos nossos? A fotografia retrata alguma discriminação ou violação de direitos? Há alguma coisa que pareça prejudicar a dignidade humana? O quê? Qual (is) artigo (s) da DUDH (ou outros instrumentos legais) você associaria a fotografia? O que diz o (s) artigo (s)? Parte das respostas dos licenciandos às questões supracitadas foi organizada num texto (um texto para cada sujeito de pesquisa), também destacamos os excertos concernentes a uma ou outra resposta, os quais foram analisados.

Neste trabalho, trouxemos para a discussão as produções textuais relativas a duas fotos reproduções disponibilizadas, aquelas que "falavam" do trabalho infantil, precisamente de um licenciando e uma licencianda, para problematizar os desdobramentos vinculados à violação dos direitos humanos e à dignidade humana. Esse material empírico foi submetido à análise interpretativa (CRESWELL, 2014), justamente quanto à pertinência das ponderações, principalmente a luz da DUDH, entre outros documentos. 
Cabe ressaltar, que os sujeitos da pesquisa, assinaram o Termo de Consentimento Livre e Esclarecido (TCLE). Nele constavam objetivos, metodologia, benefícios e possíveis riscos da pesquisa para as mesmas. Também realizamos os devidos esclarecimentos sobre dúvidas da pesquisa. Por fim, destacamos que, neste texto, os sujeitos da pesquisa foram identificados pelas três primeiras letras do sobrenome, acrescido das iniciais dos nomes, com objetivo de resguardar suas identidades.

\section{Uma necessária abordagem aos direitos humanos no ensino de ciências}

A atual sociedade, de um modo geral, tem trilhado por caminhos que naturalizam os acontecimentos degradantes da vida cotidiana, os quais precisam ser problematizados a luz dos direitos humanos. Podemos referir, por exemplo, que "[...] aceitamos a pobreza e a desigualdade como um dado natural [...] aceitamos a separação entre a lógica do mercado e a lógica dos direitos humanos e da defesa da cidadania [...]" (CACCIA BAVA, 2002, p. 80).

Ao naturalizar tais aspectos, entre muitos outros, esvaziam-se, por exemplo, as possibilidades de uma efetiva integração do ambiente escolar à realidade em suas múltiplas dimensões (social, cultural, econômica, ambiental, entre outras), na sua apreensão crítica. Temos que reconhecer, por outro lado, que a educação ainda "[...] é extremamente centrada na valorização do cognitivo, do racional, da acumulação de informações" (STORI, 2003, p. 11).

Ao trazer as fotos reproduções para o contexto da sala de aula, precisamente na formação inicial de professores que ensinam ciências, buscamos problematizar cenários sociais vigentes, "sentir" as misérias humanas. O "trabalho infantil" representa uma delas. Então, para suscitar discussões mais complexas ao ensino, lançamos mão de conteúdos afeitos aos direitos humanos, na perspectiva da formação para a cidadania.

Cabe destacar, que a formação para cidadania constitui-se aspecto importante, ao pensarmos em qualificar o ensino e a formação de professores. Entendemos que, para promover uma educação voltada à cidadania devemos tratar temáticas com significação social, notadamente sob o ponto de vista da ética e dos valores humanos, de modo que possamos dar condições para que os sujeitos aprendentes desenvolvam sua capacidade crítica em face da realidade social e, ao mesmo tempo, "conduzi-los" ao estranhamento das situações degradantes do cotidiano. É nesse contexto, que a formação "[...] de sujeitos de direitos afirma a busca pelo saber/conhecer os direitos [...]" (OLIVEIRA; QUEIROZ, 2015, p. 56). Mesmo porque, "[...] a grande maioria da população mundial não é sujeito de direitos humanos. É objeto de discurso de direitos humanos" (SANTOS, 2013, p. 15), o que nos "obriga" a problematizar este contexto.

A partir das escolhas das fotos reproduções abaixo apresentadas, vinculadas à temática "Trabalho infantil", o licenciando e a licencianda, levando em consideração o conjunto de questões apresentada na atividade, como explicitado na seção metodológica, apresentaram seus ajuizamentos, os quais foram organizados, em parte, nos textos que se seguem e outros 
em alguns excertos. Particularmente, as duas fotos reproduções sobre o trabalho infantil buscavam trazer para a cena de sala de aula, a estreita relação entre "[...] vida, desemprego, trabalho precarizado, desumano e formação-deformação [...]" (ARROYO, 2015, p. 22), de modo a ponderar sobre este estado de coisas. Vejamos, então, uma das fotos reproduções e as manifestações decorrentes da sua apreciação.

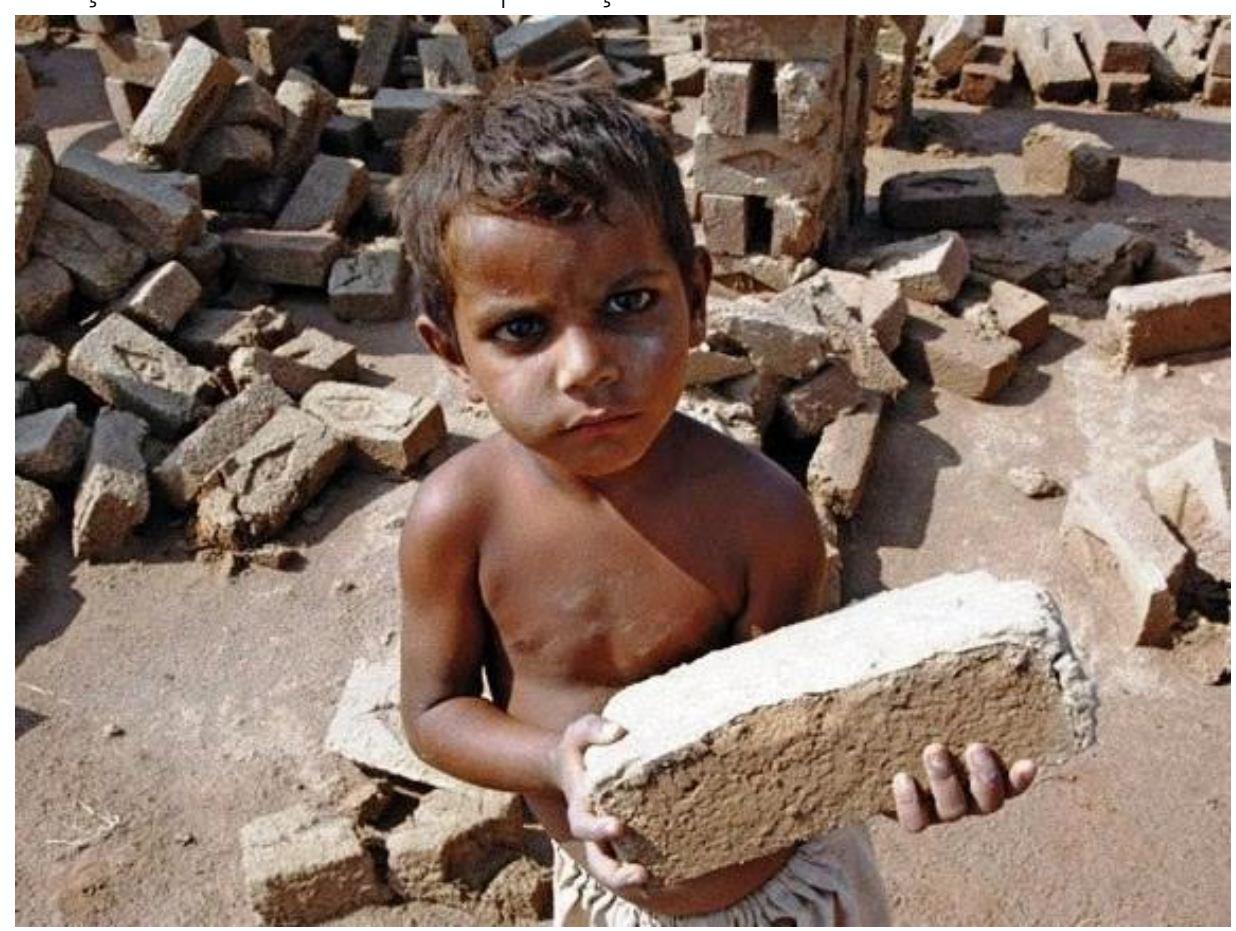

Foto reprodução: exploração do trabalho infantil $(A)^{5}$

Fonte: Cristina Vinagre, 17 de julho de 2017.

Escolhi essa fotografia porque está relacionada ao trabalho infantil [...] um grande problema social, pois milhares de crianças deixam de ir à escola para trabalhar e, assim, têm seus direitos violados. O fotografo quis mostra que o trabalho infantil ainda está presente em nosso país e nossas crianças e adolescentes são expostos a esta situação, apesar do mesmo ser considerado ilegal. O que me é familiar é que [...] as famílias carentes ainda tem a cultura de expor suas crianças ao trabalho infantil, no intuito de que elas ajudem na complementação da renda familiar. [...]. Vejo as crianças trabalhando vendendo detergente no meu bairro [...] acompanhada dos seus pais [...] como fazer algo se na realidade não existe emprego para os pais dessas crianças para manter sua família com dignidade? Acredito que essas crianças sentem vontade de viver como crianças [...] elas querem brincar, ter direito a escola e dignidade para exercer sua cidadania. Viverão com dificuldades de realizar seus sonhos, pois não terão as mesmas oportunidades das crianças que vivem uma infância com seus direitos garantidos. Toda criança e adolescente tem direito à vida, à saúde, a

\footnotetext{
5 Disponível em: <http://www.esvilela.pt/casaeuropa/index.php/2017/07/17/exploracao-infantil/>. Acesso em: 20 out. 2018.
} 
liberdade, respeito e dignidade, à família, a educação, cultura, esporte e lazer. O que prejudica a dignidade humana são as consequências do trabalho na vida da criança [...] torna a criança vulnerável em vários aspectos, incluindo saúde, exposição à violência [...] acidentes (SAN, R. S.).

Podemos depreender do texto acima, um repertório de significações. Em linhas gerais, alguns aspectos elencados pela licencianda remetem a indignação e a impotência para o referido estado de coisas. Outros se referem à constatação da usurpação e da negação dos direitos fundamentais do ser humano (a criança). No texto acima, a licencianda SAN faz referência a um conjunto de elementos que corroboram com a perspectiva da indissociabilidade dos direitos na garantia da dignidade humana.

Cabe destacar, que a licencianda SAN associa o trabalho infantil à necessidade da família de complementação do orçamento familiar. De fato, segundo a UNICEF (2009, p. 60), as questões econômicas interferem abertamente nos "[...] direitos da criança à sobrevivência, ao desenvolvimento, à proteção e à participação". No mesmo sentido, podemos referir que a "[...] precarização da vida familiar, na escassez de trabalho, no desemprego dos pais, as crianças são levadas a serem sujeitos ativos de trabalho para a sobrevivência pessoal e familiar" (ARROYO, 2015, p. 23).

Temos aqui que considerar que as condições socioeconômicas básicas, constitui-se aspecto importante para garantir a dignidade humana, "[...] não só por meios de leis, mas pela obrigatória e correta implementação de políticas públicas, de programas de ação do Estado" (BRASIL, 2007, p. 15). Desse modo, podemos avaliar que as insuficiências concernentes "[...] à alimentação, ao vestuário, ao trabalho, à moradia e à educação como os direitos relacionados à exclusão pela pobreza, cuja consequência é a violação do direito mais básico de todos: o direito à vida" (GARATE, 2007, p. 156), representam contextos de escassez, materializado pela desigualdade, entre outros aspectos (COMPARATO, 2004).

Para Font e Rufí (2006), a América Latina é uma das regiões mais desiguais do mundo. Países como o Brasil e outros da América Latina são indicados como um antiexemplo:

Na terra mais desigual do mundo, a equidade parece não ter muita importância na busca de soluções para os difíceis problemas econômicos e sociais [...] onde a América Latina é vista com freqüência como o caso "antiexemplar" mais relevante em matéria dos efeitos regressivos decorrentes de altos níveis de desigualdade (KLIKSBERG, 2002, p. 15).

Cabe destacar, neste ponto, que a licencianda SAN se contrapôs ao observado na foto reprodução, evocando, em outro momento de construção textual, o $9^{\circ}$ princípio, dos dez proclamados na Declaração Universal dos Direitos da Criança (DUDC) (UNICEF, 1959, p. 3), que se apresenta nos seguintes termos: "Nenhuma criança deverá sofrer por pouco caso dos responsáveis ou do governo, nem por crueldade e exploração. Nenhuma criança deverá trabalhar antes da idade mínima, nem será levada a fazer atividades que prejudiquem sua saúde, educação e desenvolvimento". Note-se aqui, que a indivisibilidade dos direitos é inescapável. 
Assim, pensar em trazer para o espaço de formação de professores, questões postas, por exemplo, por situações mortificantes, vivenciadas por seres humanos, é contribuir para a problematização de ideias e de valores reservados aos Direitos Humanos. Nesse contexto, cabe referir o seguinte:

O tema Direitos Humanos na Educação em Ciências surge como uma feliz comunhão entre campos de trabalho, valores e projetos de realidades construídas no tecer dos encontros e desencontros em uma época na qual a consciência da necessidade de formar professores de Ciências torna-se mais latente (OLIVEIRA; QUEIROZ, 2015, p. 17).

A abordagem do tema "direitos humanos", na formação inicial de professores, amplia o campo de abordagem do ensino para além dos conteúdos de ciências, no sentido de "[...] propiciar o incentivo necessário à construção de uma consciência de que todos são responsáveis pelo respeito à dignidade uns dos outros, de tal modo que a degradação de um indivíduo degrada a condição humana dos demais" (MUSEGANTE, 2019, p. 7). Passemos, então, para outra foto reprodução, com destaque as ponderações decorrentes de sua apreciação.

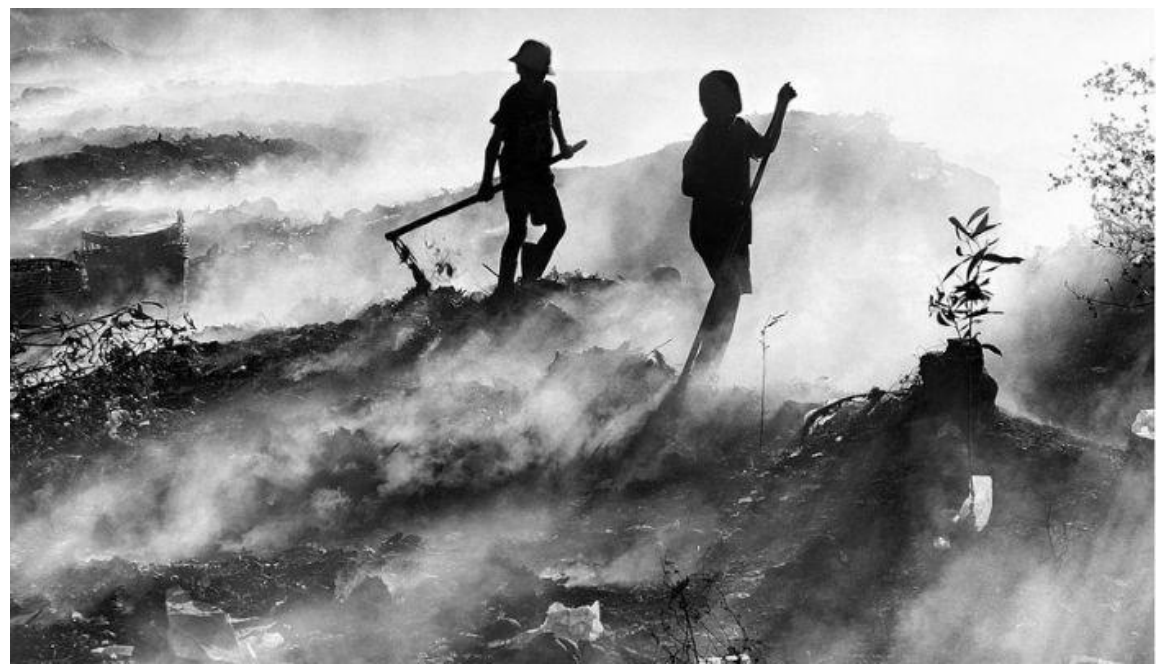

Foto reprodução: exploração do trabalho infantil $(B)^{6}$

Fonte: Juliana Sada, do Promenino, 30 de novembro de 2016.

Ao olhar todas as fotos, essa foi a primeira que chamou minha atenção. Porque trabalho infantil foi algo que sempre me tocou. Creio que o fotógrafo quis mostrar uma realidade que muitos brasileiros ainda fecham os olhos ao se depararem com ela. Já vi muitas cenas como essas ao viajar para o interior, crianças que passam as manhãs em roças ao invés da escola.

\footnotetext{
6 Disponível em: < http://fundacaotelefonica.org.br/promenino/trabalhoinfantil/noticia/trabalho-infantil-impedeque-direitos-humanos-fundamentais-sejam-garantidos/>. Acesso em: 20 out. 2018.
} 
Ao limparem o terreno após a queimada do local, a cena é exatamente idêntica a essa da foto. O que mais me impressionou, foi quando fui conversar com algumas delas e o que disseram foi quase um choque [...] elas preferiam a roça a ir estudar, por vontade própria. Diziam que a escola era chata e/ou que era melhor ganhar dinheirinho na roça do que perder tempo indo para a escola. Mas ouvi também que iam a mando dos pais, que é mais comum no trabalho infantil (LEA, R.S)

Trazemos para discussão, como um aparte, o fato de que reconhecemos que a maioria das aulas apresenta-se "[...] sem questionamento, sem poesia, sem imaginação, sem ludicidade e desinteressante" (SANTOS, 2019, p. 13, destaque nosso); certamente, reflexo da tendência tradicional de ensino que se pauta, quase que exclusivamente, na exposição de conteúdos, em verdadeiros monólogos; além do mais, desvinculados da realidade dos alunos. Alguns trabalhos de pesquisa relatam o cenário desestimulador da sala de aula, a exemplo da pesquisa de Santos (2019, p. 12, destaque nosso), que ao indagar o que as crianças mudariam na escola, defronta-se com as seguintes respostas:

[...] podia parar de copiar texto. A gente copia muito texto. A professora sempre pede para a gente copiar as coisas (Gabriele, 10 anos). Eu gosto de correr, brincar de futebol. A escola podia deixar a gente brincar mais. Eu gosto da escola, mas às vezes é chata, pois a gente não brinca (Kaue, 10 anos).

A narrativa de Kaue (SANTOS, 2019) corrobora com a apreensão do licenciando, quando em conversa com uma criança, na condição de trabalho infantil. Por outro lado, e na consideração de que se deve "[...] propiciar ao aluno a capacidade de construir e transformar, de forma independente, a atividade da própria vida, ser seu verdadeiro sujeito social [...]" (SANTOS, 2019, p. 13). Mas como fazê-lo, se, a maioria dos professores, empenham-se na tarefa de dar conta de extensos conteúdos científicos, em detrimento daqueles que aproximam os alunos aos contextos de vida da sociedade. Por seu turno, os espaços educacionais precisam contemplar uma agenda pedagógica para tratar questões socialmente relevantes, com significado para os sujeitos aprendentes, a exemplo do aqui fizemos na formação de professores que ensinam ciências - uma aproximação ao campo social.

Retomando as análises referentes ao trabalho infantil, propriamente dita, podemos observar que, para o licenciando LEA, o trabalho infantil é uma realidade preocupante. De fato, segundo dados do IBGE (BRASIL 2016), mais de 2,6 milhões de crianças e adolescentes encontram-se exercendo algum tipo de trabalho. Essas crianças e adolescentes por trabalharem perdem o direito de estudar, de brincar e de se desenvolver, condições avessas à garantia, por exemplo, da criança como sujeito de direitos.

No reconhecimento de contextos degradantes da condição humana, é importante que na formação de professores, desenvolvam-se práticas vivenciais significativas. Para Candau et al. $(2013$, p. 77$)$, 
[...] torna-se imprescindível na formação de professores(as) desenvolver processos que permitam articular diferentes dimensões - cognitiva, afetiva, e sociopolítica - fundamentais para a Educação em Direitos Humanos, assim como usar estratégias pedagógicas ativas, participativas e de construção coletiva que favoreçam educar-nos em Direitos Humanos.

Assim, as possibilidades de materializarmos o exercício de juízos reflexivos sobre os vários contextos da sociedade, encaminhando-o para a compreensão dos Direitos Humanos (BRASIL, 2013), configura-se aspecto importante na formação de professores. Mesmo porque, "esse exercício", em sala de aula, coloca em evidência realidades que importam em violação dos direitos humanos.

A sensibilização para o reconhecimento de contextos degradantes da condição humana só será possível se nós nos propusermos, na formação de professores, desenvolver um trabalho pedagógico que propicie vivências significativas no espaço de sala de aula. Estamos nos referindo às possibilidades de materializarmos o "[...] exercício de juízos reflexivos sobre as relações entre os contextos sociais, culturais, econômicos e políticos [...] coerentes com os Direitos Humanos" (BRASIL, 2013, p. 53).

Também, por outro lado, colaboramos para o resgate da sensibilidade humana, tão necessário aos tempos líquidos (BAUMAN, 2001; 2007); inclusive, com discussões sobre a naturalização das questões sociais e seus reflexos sobre violação dos direitos. Podemos referir que, a formação de professores, na perspectiva da educação em direitos humanos, contribui para reflexões sobre realidades próximas ou distantes, de modo que se possam reconhecer a violação destes direitos, expressas em várias circunstâncias degradantes, que são impingidas à sociedade.

Aquino (2016, p. 85), buscando compreender a perda de significado da dignidade em tempos líquidos, apoiado nos escritos de Bauman, refere que este "[...] denunciou como a liquidez do Tempo, das Relações Humanas e de sua Responsabilidade, não evidenciam o seu aperfeiçoamento histórico a fim de traduzir novos significados, maior disseminação e preservação da Dignidade da Pessoa Humana". Tal aperfeiçoamento seria "[...] expressão de justiça, de reconhecimento ao fato que as pessoas não vivem em condições apropriadas [...]" (AQUINO, 2016, p. 86).

Cabe destacar, neste ponto, que os professores de ciências, em geral, têm poucas oportunidades, na formação inicial, de entrarem em contato com temas afeitos aos direitos humanos e de amadurecerem este debate; portanto, constitui-se desafio tanto à formação de professores quanto aos formadores de professores (CHINELLI, 2016). O empreendimento formativo de aproximar o campo das ciências naturais do campo social, embora não seja tarefa fácil, mostra-se relevante, em face do recrudescimento de violações generalizadas ocorrentes na nossa sociedade.

A educação em ciências é aqui "[...] assumida como um pretexto e um contexto para o desenvolvimento de conhecimentos, capacidades e atitudes que capacitem os cidadãos para enfrentarem os desafios e as injustiças do seu quotidiano" (REIS, 2019, p. xv). Como base 
nesses pressupostos, promovemos intensa discussão, em sala de aula, sobre as questões arroladas nas apreciações dos licenciandos, aqui tratadas, bem como de outros licenciandos, relativas às fotos reproduções, em um processo de formação para a cidadania, com destaque aos direitos humanos cujo abrigo nos conduz a consideração da dignidade da pessoa humana.

\section{Considerações finais}

Atualmente, a construção de uma cultura de direitos e de cidadania constitui-se grande desafio a sociedade, particularmente para professores, na intensa tarefa de formação de cidadãos. Vivenciamos na contemporaneidade, os mais variados discursos de ódio e de ofensivas à democracia e aos direitos já conquistados. Nesse contexto, consideramos a formação de professores um campo estratégico para reflexões sobre esse estado de coisas, de modo a contribuir para a disseminação de princípios e de valores alocados nos Direitos Humanos, inclusive, no âmbito da educação básica.

Assim, procuramos incorporar na experiência formativa, junto a futuros professores que ensinarão ciências, o confronto com a realidade, na apreensão das assimetrias sociais e seus desdobramentos relativos à violação dos direitos, ao entendermos que o ensino de ciências deve atender os requisitos tanto da dinâmica científica quanto da social. Ademais, há que se ter conhecimentos das barreiras estruturais e sociais que se apresentam à sociedade para usufruir os direitos humanos, de modo que os mecanismos que reproduzem a desigualdades sejam também explicitados.

A perspectiva não foi formar um professor especialista em Direito, mas tão somente garantir o saber/conhecer os direitos, na intenção de configurar um ambiente de contrariedade face à existência de populações de sacrifício, de modo que os direitos humanos interrogou o trabalho infantil. Em geral, os discentes, e não somente aquelas que aqui nos reportamos, apropriaram-se qualificadamente dos princípios e dos valores dos direitos humanos, abandonando, naquele momento, a perspectiva de relativização das situações que implicavam em violação destes direitos. $O$ ensino de ciências precisa envidar esforços para dar visibilidade, por exemplo, a exploração do trabalho infantil, a violência contra a mulher, a discriminação, a insegurança generalizada, entre outros eventos que colocam os seres humanos em condições de vulnerabilidade no exercício dos seus direitos; perspectiva é fortalecer o conteúdo dos direitos humanos.

A postura frente à experiência formativa voltou-se para a sensibilidade da condição humana. Desse modo, a formação dos professores que ensinam Ciências, a partir da perspectiva da Educação em Direitos Humanos, possibilitou que temática como dignidade da pessoa humana fosse considerada em um plano real e dialógico, bem como internalizada por aqueles que atuarão em espaços de educação formal e não formal, favorecendo a constituição de uma cultura de direitos humanos, de maneira que se exercitou, coletivamente, a solidariedade, o respeito, a diversidade e a tolerância. 


\section{Referências}

AFONSO, M. R. Trabalhar os direitos humanos no contexto escolar: da compreensão aos instrumentos. Lisboa: DGIDC/ME, 2005. Disponível em: <http://www.dhnet.org.br/dados/ livros/edh/portugal/rosa_afonso/livro_rosa_afonso.pdf>. Acesso em: 12 mar. 2018.

AQUINO, S. R. F. Bauman e a crítica sobre a perda da dignidade da pessoa humana em tempos líquidos. Revista Húmus, Maranhão, v. 6, n. 18, p. 70-88, 2016.

ARROYO, M. G. A infância repõe o trabalho na agenda pedagógica. In: ARROYO, M. G.; VIELLA, M. A. L.; SILVA, M. R. (Orgs.) Trabalho infância: exercícios tensos de ser criança haverá espaço na agenda pedagógica? Petrópolis, RJ: Vozes, 2015

AWAD, F. O princípio constitucional da dignidade da pessoa humana. Justiça do Direito, Passo Fundo, v. 20, n. 1, p. 111-120, 2006.

BAUMAN, Z. Modernidade líquida. Tradução de Plínio Dentzien. Rio de Janeiro: Jorge Zahar, 2001.

BAUMAN, Z. Tempos líquidos. Tradução de Carlos Alberto Medeiros. Rio de Janeiro: Jorge Zahar, 2007.

BRASIL. Pesquisa Nacional por Amostra de Domicílios: síntese de indicadores. 2015. IBGE. Coordenação de Trabalho e Rendimento. Rio de Janeiro: IBGE, 2016.

BRASIL. A Declaração Universal dos Direitos Humanos e os Objetivos de Desenvolvimento Sustentável: avanços e desafios. Brasília: Ministério dos Direitos Humanos, 2018a.

BRASIL. Ministério da Educação. Base Nacional Comum Curricular. Ministério da Educação, Brasília, DF: MEC, 2017. Disponível em: <http://basenacionalcomum.mec.gov.br/ images/BNCC_El_EF_110518_versaofinal_site.pdf>. Acesso em: 20 nov. 2019.

BRASIL. Constituição Federal. 1988. Vade-mecum. São Paulo: Saraiva, 2016.

BRASIL. Declaração Universal dos Direitos Humanos. Brasília: UNESCO do Brasil, 1998.

BRASIL. ECA. Lei n 8.069, de 13 de julho de 1990. Alagoas: Conselho Estadual dos Direitos da Criança e do Adolescente, 2010.

BRASIL. Programa Ética e Cidadania. Construindo valores na escola e na sociedade: inclusão e exclusão social. Módulo 3: Direitos Humanos. Brasília: Ministério da Educação, Secretaria de Educação Básica, 2007.

BRASIL. Secretaria de Direitos Humanos. Caderno de Educação em Direitos Humanos. Educação em Direitos Humanos: Diretrizes Nacionais. Brasília: Coordenação Geral de Educação em SDH/PR, Direitos Humanos, Secretaria Nacional de Promoção e Defesa dos Direitos Humanos, 2013.

CANDAU, V. M. F.; SACAVINO, S. B. Educação em direitos humanos e formação de educadores. Educação, Porto Alegre, v. 36, n. 1, p. 59-66, 2013. 
CANDAU, V. M.; PAULO, I.; ANDRADE, M.; SACAVINO, M. C. L. S.; AMORIM, V. Formação inicial de professores (as) e educação em diretos humanos. In: CANDAU, V. M.; PAULO, I.; ANDRADE, M.; SACAVINO, M. C. L. S.; AMORIM, V. (Org.). Educação em diretos humanos e a formação de professores (as). São Paulo: Cortez, 2013. p. 55-77.

CACCIA BAVA, S. Participação, representação e novas formas de diálogo público. In: CACCIA BAVA, S.; PAULICS, V.; SPINK, P. (Org.). Novos contornos da gestão local: conceitos em construção. São Paulo, Pólis; Programa Gestão Pública e Cidadania/EAESP/FGV, 2002. p.75103.

CHINELLI, M. V.; OLIVEIRA, V. S. Água, direito humano fundamental: para que indivíduos em situação vulnerável se façam sujeitos de direitos. In: OLIVEIRA, R. D. V. L.; QUEIROZ, G. R. P. C. (Org.). Conteúdos cordiais: química humanizada para uma escola se mordaça, 2017. p. 7588.

COMPARATO, F. K. O princípio da igualdade e da escola. In: CARVALHO, J. S. (Org.). Educação, cidadania e direitos humanos. Petrópolis: Vozes, 2004. p. 66-84.

CRESWELL, J. W. Investigação qualitativa e projeto de pesquisa: escolhendo entre cinco abordagens. Tradução: Sandra Mallmann da Rosa. 3 ed. Porto Alegre: Penso, 2014.

FERNANDES, A. V. M.; PALUDETO, M. C. Educação e direitos humanos: desafios para a escola contemporânea. Cadernos CEDES, Campinas, v. 30, n. 81, p. 233-249, 2010.

FONT, J. N.; RUFÍ, J. V. Geopolítica, identidade e globalização. São Paulo: Annablume, 2006.

GARATE, E. S. O longo caminho da luta contra a pobreza e seu alentador encontro com os direitos humanos. SUR - Revista Internacional de Direitos Humanos, São Paulo, n. 7, a. 4, p.152-167, 2007.

GORCZEVSKI, C.; KONRAD, L. R. A educação e o plano nacional de educação em direitos humanos: efetivando os direitos fundamentais no Brasil. Revista do Direito UNISC, Santa Cruz do Sul, n. 39, p. 18-42, 2013

KLIKSBERG, B. Desigualdade na América latina: o debate adiado. 3ª Ed. São Paulo: Cortez; Brasília, DF: UNESCO, 2002.

MARSHALL, T. H. Cidadania, classe social e status. Rio de Janeiro: Zahar, 1967.

MINAYO, M. C. de. S. Trabalho de campo: contexto de observação, interação e descoberta. In: MINAYO, M. C. de. S. (Org.). Pesquisa social: teoria, método e criatividade. Petrópolis, RJ: Vozes, 2016. p. 56-71. (Série Manuais Acadêmicos).

MUSEGANTE, M. L. L. Humanização na educação básica, a contribuição dos direitos humanos revista brasileira de educação básica. Revista Brasileira de Educação Básica, Belo Horizonte, v. 4, n. 12, p. 1-8, 2019. 
OLIVEIRA, R. D. V. L. Educação em Ciências e Direitos Humanos: algumas percepções e uma luta constante. In: OLIVEIRA, R. D. V. L; QUEIROZ, G. R. P. C. Educação em Ciências e Direitos Humanos: reflexão-ação em/para uma sociedade plural, 2013. p.19-40.

OlIVEIRA, R. D. V. L. de; QUEIROZ, G. R. P. C. (Org.). Olhares sobre a (in)diferença: formar-se professor de ciências a partir de uma perspectiva de Educação em Direitos Humanos. São Paulo: Livraria da Física, 2015.

REIS, P. Prefácio. In: TeIXEIRA, P. P.; OlIVEIRA, R. D. V. L.; QUEIROZ, G. R. P. C. (Org.). Conteúdos cordiais: biologia humanizada para uma escola se mordaça. São Paulo: Editora Livraria da Física, 2019. p. xv.

SADA, J. Exploração trabalho infantil. Foto reprodução. 2016. Disponível em: < http://fundacaotelefonica.org.br/promenino/trabalhoinfantil/noticia/trabalho-infantilimpede-que-direitos-humanos-fundamentais-sejam-garantidos/>. Acesso em: 20 out. 2018. SANTOS, A. R. J. O que as crianças dizem sobre a escola? Educação, Santa Maria, v. 44, p. 118, 2019.

SANTOS, B. de S. Se Deus fosse um ativista dos direitos humanos. São Paulo: Cortez, 2013.

STORI, N. Apresentação. In: STORI, N. O despertar da sensibilidade na educação. São Paulo: Instituto Presbiteriano Mackensie; Cultura Acadêmica Editora, 2003. p. 11-14.

TOSI, G.; FERREIRA, L. F. G. Educação em direitos humanos nos sistemas internacional e nacional. In: FLORES, E. C.; FERREIRA, F. L. F. G.; MELO, V. L. B. (Org.). Educação em Direitos Humanos \& Educação para os Direitos Humanos. João Pessoa/PB: Editora Universitária da UFPB, 2014. p. 37-63.

UNICEF. Declaração Universal dos Direitos das Crianças. 1959. Disponível em: < http://bvsms.saude.gov.br/bvs/publicacoes/declaracao_universal_direitos_crianca.pdf. Acesso em: 15 mai. 2019.

UNICEF. Situação mundial da infância (edição especial): celebrando 20 anos da Convenção sobre os Direitos da Criança. 2009. Disponível em: <http://www.unicef.org/ brazil/pt/sowc_20anosCDC.pdf>. Acesso em: 15 mai. 2019.

VINAGRE, C. Exploração do trabalho infantil. Foto reprodução. 2017. Disponível em: <http://www.esvilela.pt/casaeuropa/index.php/2017/07/17/exploracao-infantil/>. Acesso em: 20 out. 2018. 